\title{
RESEARCH
}

\section{Perceived Motivating Factors and Barriers for the Completion of Postgraduate Training Among American Pharmacy Students Prior to Beginning Advanced Pharmacy Practice Experiences}

Drayton A. Hammond, PharmD, MBA, ${ }^{a}$ Douglas R. Oyler, PharmD, ${ }^{\mathrm{b}}$ John W. Devlin, PharmD, ${ }^{\mathrm{c}}$

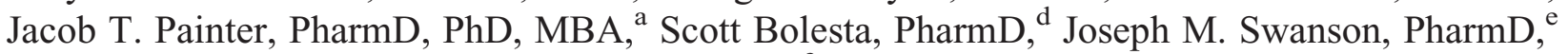
Brett J. Bailey, PharmD, ${ }^{\text {a }}$ Trisha Branan, PharmD, ${ }^{f}$ Jeffrey F. Barletta, PharmD, ${ }^{\mathrm{g}}$ Brianne Dunn, PharmD, Jason S. Haney, PharmD, ${ }^{i}$ Paul Juang, PharmD, ${ }^{j}$ Sandra L. Kane-Gill, PharmD, MS, ${ }^{k}$ Tyree H. Kiser, PharmD, ${ }^{1}$ Hira Shafeeq, PharmD, ${ }^{\mathrm{m}}$ Debra Skaar, PharmD, ${ }^{\mathrm{n}}$ Pamela Smithburger, PharmD, MS, ${ }^{\mathrm{k}}$ Jodi Taylor, PharmD ${ }^{\mathrm{o}}$

${ }^{a}$ University of Arkansas for Medical Sciences College of Pharmacy, Little Rock, Arkansas

${ }^{\mathrm{b}}$ University of Kentucky, Lexington, Kentucky

${ }^{\mathrm{c}}$ Northeastern University, Boston, Massachusetts

${ }^{\mathrm{d}}$ Nesbitt School of Pharmacy, Wilkes University, Wilkes-Barre, Pennsylvania

${ }^{\mathrm{e}}$ University of Tennessee College of Pharmacy, Memphis, Tennessee

${ }^{\mathrm{f}}$ University of Georgia College of Pharmacy, Athens, Georgia

g Midwestern University, College of Pharmacy-Glendale, Glendale, Arizona

${ }^{\mathrm{h}}$ South Carolina College of Pharmacy - USC Campus, Columbia, South Carolina

${ }^{\mathrm{i}}$ South Carolina College of Pharmacy - Charleston, South Carolina

${ }^{j}$ St. Louis College of Pharmacy, St. Louis, Missouri

${ }^{\mathrm{k}}$ University of Pittsburgh School of Pharmacy, Pittsburgh, Pennsylvania

${ }^{1}$ University of Colorado School of Pharmacy, Aurora, Colorado

${ }^{m}$ St. John's University College of Pharmacy and Health Sciences, New York, New York

${ }^{\mathrm{n}}$ University of Minnesota College of Pharmacy, Minneapolis, Minnesota

${ }^{\circ}$ Union University School of Pharmacy, Jackson, Tennessee

Submitted March 30, 2016; accepted August 22, 2016; published June 2017.

Objective. To examine perceived motivating factors and barriers (MFB) to postgraduate training (PGT) pursuit among pharmacy students.

Methods. Third-year pharmacy students at 13 schools of pharmacy provided demographics and their plan and perceived MFBs for pursuing PGT. Responses were characterized using descriptive statistics. Kruskal-Wallis equality-of-proportions rank tests determined if differences in perceived MFBs existed between students based on plan to pursue PGT.

Results. Among 1218 (69.5\%) respondents, 37.1\% planned to pursue PGT (32.9\% did not, 30\% were undecided). Students introduced to PGT prior to beginning pharmacy school more frequently planned to pursue PGT. More students who planned to pursue PGT had hospital work experience. The primary PGT rationale was, "I desire to gain more knowledge and experience." Student debt was the most commonly cited barrier. Conclusion. Introducing pharmacy students early to PGT options and establishing work experiences in the hospital setting may increase students' desire to pursue PGT.

Keywords: postgraduate training, residency, motivating factors, motivating barriers

\section{INTRODUCTION}

The American College of Clinical Pharmacy (ACCP) and the American Society of Health-System Pharmacists (ASHP) recommend residency training for all pharmacists

Corresponding Author: Drayton A. Hammond, University of Arkansas for Medical Sciences, 4301 West Markham St., Slot 522, Little Rock, AR 72205. Tel: 501-686-6683. Fax: 501-296-1168. E-mail: DAHammond@uams.edu who provide direct patient care. ${ }^{1,2}$ By 2020, ASHP advocates that all new pharmacy graduates who plan to provide direct patient care complete an ASHP-accredited postgraduate year 1 (PGY1) pharmacy residency. ${ }^{1}$ Because all new pharmacy graduates will not provide direct patient care, completion of postgraduate training (PGT) will not be a requisite to practice as a pharmacist in the near future. Nonetheless, preparation for PGT, including residency and 


\section{American Journal of Pharmaceutical Education 2017; 81 (5) Article 90.}

fellowship training and graduate school, should begin during the doctor of pharmacy program. To this end, the American Association of Colleges of Pharmacy recommends that schools and colleges of pharmacy take a proactive leadership role to develop and enhance residencies. ${ }^{3}$

Current standards from the Accreditation Council for Pharmacy Education (ACPE) advocate that PGT be promoted in pharmacy schools. Specifically, Standard 14.4 of the ACPE Standards 2016 calls for doctor of pharmacy programs to provide students with academic advising, curricular and career pathway counseling, and information regarding postgraduate education and training. ${ }^{4} \mathrm{Ad}-$ ditionally, graduates from colleges of pharmacy should be self-aware of their personal knowledge, skills, and abilities that could enhance their professional growth. ${ }^{4}$ Curricular and co-curricular programs focused on supporting students' pursuit of PGT have been developed within colleges of pharmacy to address these needs. ${ }^{5-10}$

Despite widespread efforts to promote PGT opportunities to pharmacy students, ${ }^{5-10}$ the number of students entering PGT remains highly variable among colleges. This has led to growing research surrounding the effect these efforts have on the decision by students to pursue PGT and those factors that influence the PGT decision. Surprisingly, these research efforts have focused on the perceptions of pharmacy faculty, residents, and fellows rather than the perceptions of the student themselves. ${ }^{11,12}$ For example, the barriers to PGT most frequently reported by faculty, residents, and fellows were students' financial obligations and the availability of relevant jobs after PGT completion. ${ }^{11}$ However, there are many potential factors related to PGT pursuit that a faculty member is clearly not well-suited to evaluate and likely will infer their personal bias and experiences when trying to understand factors affecting the pharmacy student of today.

The factors that lead or dissuade students to apply for a PGT position remain unclear. Given the long and iterative process by which students decide to pursue PGT, it is critical to survey students (rather than residents/fellows or faculty) about the factors that motivate them to pursue PGT. Given this current gap in knowledge, we sought to determine the perceived motivating factors and barriers to the pursuit of PGT opportunities among third professional year pharmacy students at a cross section of colleges of pharmacy in the US.

\section{METHODS}

This study was an investigational review boardapproved multicenter survey of pharmacy students in the final semesters of their didactic curriculum. Students were recruited at 13 accredited colleges of pharmacy throughout the United States. The 13 colleges of pharmacy (eight public and five private) were chosen as a representative sample of all accredited colleges of pharmacy. ${ }^{13}$ One college exclusively offers an accelerated program, and four colleges begin advanced pharmacy practice experiences in the sixth of eight semesters. None of the colleges offer early assurance admission to applicants completing high school or require a bachelor degree for admission. The geographical locations of these 13 colleges typified the distribution of ACPE-accredited institutions across the US (Eastern 23\%, Southern 46\%, Midwestern 15\%, and Western 15\%) and were chosen as a convenience sample that originated from collegial relationships among co-investigators. Survey questions were modified from previously published surveys of residents, fellows, and faculty members regarding students' motivating factors and barriers to PGT. ${ }^{11,12}$ The survey tool included questions regarding student demographics, plans for pursuing PGT, and potential motivating factors and barriers to pursuing PGT (Appendix 1). For the purpose of the survey, a motivating factor was deemed to be an item that could be construed as a reason to pursue PGT. A barrier was deemed to be an item that could be construed as a reason not to pursue PGT. Motivating factors and barriers were evaluated using a 5-point Likert scale $(1=$ strongly disagree, $5=$ strongly agree $)$. Ten faculty members in departments of pharmacy practice and pharmaceutical sciences and 10 students in their final year of a professional pharmacy program, who were not directly involved in the study, validated the survey tool for face and content validity and provided written feedback to the survey. This led to refinement of the survey instrument.

In the spring semester of 2015, co-investigators administered the survey during the month prior to the start of advanced pharmacy practice experiences. Student participation in the survey was voluntary, and there were no funding and/or other incentives provided for survey completion. Students at 10 schools were offered a single opportunity to complete the survey using pen and paper, and students at the three remaining schools were provided with a link to the survey up to three times through an online survey software and insight platform (Qualtrics, Provo, UT). Data were aggregated for each institution so that all personal information that might link specific responses to individual participants was removed.

Anonymous survey responses were transferred to a central institution (University of Arkansas for Medical Sciences) for analysis using Stata 13 (Stata Corp., College Station, TX). Descriptive statistics were used to characterize student demographics and the perceived motivating factors and barriers to pursuing PGT. Based on statistical correlation and expert opinion with a majority vote, the 34 individual motivating factors and barriers items were 


\section{American Journal of Pharmaceutical Education 2017; 81 (5) Article 90.}

aggregated into five domains for ease of comparison across related items: Self-Actualization (SA), Future Employment and Potential Growth (FEP), Awareness of PGT Opportunities (AO), Internal Factors/Barriers to PGT (IFB), and External Factors/Barriers to PGT (EFB). (Appendix 2) Kruskal-Wallis equality-of-proportions rank tests were performed to determine if global differences in perceived motivating factors and barriers existed between students who indicated "yes," "no," or "undecided" to complete PGT. If a global difference were detected, relevant pairwise comparisons were made using student's $t$-test, chi-square, or Fisher's exact as appropriate based on type of data and group size. Global comparisons with $p$-values less than .05 were considered statistically significant. Bonferroni correction for multiple comparisons was used for pairwise comparisons.

\section{RESULTS}

Among 1752 surveyed students, 1218 (69.5\%) completed the instrument. Students' demographic characteristics in aggregate and by plan to pursue PGT are presented in Table 1, and colleges of pharmacy program characteristics are provided in Table 2. Overall $37.1 \%$ of students indicated they planned to pursue PGT (vs 32.9\% who did not and $30 \%$ who were undecided). Students who first learned about PGT prior to their first year in pharmacy school more frequently indicated that they planned to pursue PGT compared to those who did not plan to pursue PGT or were undecided $(35.9 \%$ vs $19.7 \%$ vs $20.9 \%, p<.001)$. Females comprised a significantly higher proportion of students who planned to pursue PGT than those who did not plan to pursue PGT (65.7\% vs $56.2 \%$, $p=.005)$ or males who planned to pursue PGT ( $65.7 \%$ vs $34.3 \%, p<.001)$. Students who planned to pursue PGT had significantly more hospital $(48.3 \%, p=.001)$ and industry $(5.2 \%, p=.003)$ work experience compared to students who did not plan to pursue PGT $(15.8 \%$ for hospital; $1.9 \%$ for industry) or who remained undecided (28.6\% for hospital; $1.4 \%$ for industry). Plans to complete PGT varied between US regions, with Midwest students more likely to pursue PGT than students in the South $(47.2 \%$ vs $31.2 \%, p<.001)$. While the proportion of

Table 1. Demographics of Survey Participants $(N=1218)$

\begin{tabular}{|c|c|c|c|c|c|}
\hline Variable $^{1}$ & Overall & Yes for PGT $(n=443)$ & No for PGT $(n=411)$ & $\begin{array}{l}\text { Undecided for } \\
\text { PGT }(n=364)\end{array}$ & $p$ value ${ }^{2}$ \\
\hline Age, years. Mean (SD) & $25.2(3.7)$ & $25.0(3.3)$ & $25.6(3.7)$ & $25.1(4.0)$ & .15 \\
\hline Male gender & $457(37.5)$ & $152(34.3)$ & $180(43.8)$ & $125(34.3)$ & .005 \\
\hline Pharmacy as first career & $1053(86.5)$ & $383(86.5)$ & $350(85.2)$ & $320(87.9)$ & .55 \\
\hline \multicolumn{6}{|l|}{ Prior degrees } \\
\hline Bachelor’s Degree & $767(63.0)$ & $287(64.8)$ & $258(62.8)$ & $222(61.0)$ & .54 \\
\hline Master's Degree & $32(2.6)$ & $16(3.6)$ & $6(1.5)$ & $10(2.7)$ & .13 \\
\hline Doctoral Degree & $10(0.8)$ & $5(1.1)$ & $3(0.7)$ & $2(0.5)$ & .73 \\
\hline Dual degree program enrollment & $79(6.5)$ & $30(6.8)$ & $24(5.8)$ & $25(6.9)$ & .13 \\
\hline \multicolumn{6}{|l|}{ Prior work experience ${ }^{3}$} \\
\hline None & $25(2.1)$ & $9(2.0)$ & $10(2.4)$ & $6(1.6)$ & .74 \\
\hline Community & $965(79.2)$ & $321(72.5)$ & $348(84.7)$ & $296(81.3)$ & .001 \\
\hline Hospital & $383(31.4)$ & $214(48.3)$ & $65(15.8)$ & $104(28.6)$ & .001 \\
\hline Industry & $36(3.0)$ & $23(5.2)$ & $8(1.9)$ & $5(1.4)$ & .003 \\
\hline Nuclear & $6(0.5)$ & $1(0.2)$ & $3(0.7)$ & $2(0.6)$ & .60 \\
\hline Home Infusion & $17(1.4)$ & $6(1.4)$ & $6(1.5)$ & $5(1.4)$ & .99 \\
\hline Non-pharmacy & $258(21.2)$ & $105(23.7)$ & $72(17.5)$ & $81(22.3)$ & .073 \\
\hline \multicolumn{6}{|l|}{ Region } \\
\hline East & $248(20.4)$ & $97(21.9)$ & $68(16.5)$ & $83(22.8)$ & .13 \\
\hline South & $584(47.9)$ & $182(41.0)$ & $235(57.2)$ & $167(45.9)$ & $<.001$ \\
\hline Midwest & $191(15.7)$ & $90(20.3)$ & $39(9.5)$ & $62(17.0)$ & $<.001$ \\
\hline West & $195(16.0)$ & $74(16.7)$ & $69(16.8)$ & $52(14.3)$ & .77 \\
\hline \multicolumn{6}{|l|}{ First learned of PGT options } \\
\hline Did not learn & $15(1.2)$ & $5(1.1)$ & $5(1.2)$ & $5(1.4)$ & .99 \\
\hline Pre-professional curriculum & $316(26.0)$ & $159(35.9)$ & $81(19.7)$ & $76(20.9)$ & $<.001$ \\
\hline $1^{\text {st }}$ professional year & $822(67.5)$ & $257(58.0)$ & $303(73.7)$ & $262(72.0)$ & $<.001$ \\
\hline $2^{\text {nd }}$ professional year & $53(4.4)$ & $18(4.1)$ & $19(4.6)$ & $16(4.4)$ & .98 \\
\hline $3^{\text {rd }}$ professional year & $11(0.9)$ & $4(0.9)$ & $3(0.7)$ & $4(1.1)$ & .99 \\
\hline Attended a public institution & $995(81.7)$ & $363(81.9)$ & $355(86.4)$ & $277(76.1)$ & .001 \\
\hline
\end{tabular}




\section{American Journal of Pharmaceutical Education 2017; 81 (5) Article 90.}

Table 2. Program Factors

\begin{tabular}{|c|c|c|c|c|c|c|}
\hline Institution & Region & Class Size & $\begin{array}{l}\text { Response } \\
\text { Rate (\%) }\end{array}$ & Electronic Survey & $\begin{array}{l}\text { Academic Medical } \\
\text { Center Affiliation }\end{array}$ & Private vs Public \\
\hline $\mathrm{A}$ & West & 150 & 23 & Yes & No & Private \\
\hline $\mathrm{C}$ & Midwest & 215 & 25 & Yes & Yes & Private \\
\hline $\mathrm{D}$ & South & 51 & 61 & Yes & Yes & Private \\
\hline $\mathrm{E}$ & South & 119 & 93 & No & Yes & Public \\
\hline $\mathrm{H}$ & South & 126 & 63 & No & Yes & Public \\
\hline I & Midwest & 158 & 87 & No & Yes & Public \\
\hline $\mathrm{J}$ & East & 135 & 61 & No & No & Private \\
\hline K & East & 109 & 99 & No & Yes & Public \\
\hline $\mathrm{L}$ & South & 153 & 78 & Yes & Yes & Public \\
\hline
\end{tabular}

students who planned to pursue PGT was similar between public and private institutions, students at private institutions were more likely to be undecided about pursuing PGT $(p=.001)$. Neither the individual college of pharmacy response rate $(p=.30)$ nor the paper versus online survey format $(p=.20)$ affected the proportion of students pursuing PGT.

The proportion of students who agreed or strongly agreed with each factor and barrier statement differed based on their likelihood for seeking PGT. (Table 3) Direct comparisons between students who indicated they planned to pursue, did not plan to pursue, and were undecided about pursuing PGT are presented in Appendix 3. Students who planned to complete PGT were statistically more likely to agree or strongly agree with motivating factors when compared to the group that did not or was undecided about pursuing PGT. (Table 3) Results reflecting classification by domain are located in Table 4.

Students who planned to pursue PGT tended to agree more strongly with statements from the SA domain as compared to other domains $(p<.001)$. The three highest-rated motivating factors for these students were grouped in the SA domain (F1, F2, and F3). These factors were related to the desire to gain more knowledge and experience (F1) and specialized training (F2), and the belief that further training is needed for the respondent's desired position (F3). The highest-rated individual barriers were those related to desire for a position that requires PGT (B18), competition for PGT positions (B13), PGT position salaries (B2), and extracurricular activities that were not competitive enough to pursue a PGT position (B15).

Among students who did not plan to pursue PGT, there were no significant differences between domains. The highest-rated individual motivating factor among students who did not plan to complete PGT was the desire to gain more knowledge and experience (F1). The highest-rated individual barriers among this cohort were those related to financial obligations (B1 and B2), competition for PGT positions (B13), and having already secured employment after graduation (B3).

Similar to students who planned to pursue PGT, students who were undecided about pursuing PGT were more likely to agree with statements from the SA domain as compared to the other domains $(p<.001)$. In descending order, the highest-rated individual motivating factors among students who were undecided were factors F1, F2, $\mathrm{F} 4$, and $\mathrm{F} 3$, and the highest-rated individual barriers were $\mathrm{B} 13, \mathrm{~B} 2$, and B1.

\section{DISCUSSION}

Students were divided or undecided on whether they planned to pursue PGT or not. Females - those with previous hospital work experience, industry work experience, or no community work experience - indicated a desire to pursue PGT significantly more often. Students who indicated a desire to pursue PGT showed better agreement with all five domains compared to the other two groups. However, those who were undecided showed better agreement than those who did not want to pursue PGT in the Self-Actualization and Future Employment and Potential Growth domains.

In addition to the financial incentives associated with performing a job, many individuals desire work that allows them to achieve autonomy, mastery, and purpose. ${ }^{14}$ Easily relatable to PGT, students planning to pursue PGT were more heavily motivated than others by the desire for SA. They had strong agreement with motivating factors F1, F2, and F3 in the SA domain. These were the three most agreed with statements overall. A similar instrument 


\section{American Journal of Pharmaceutical Education 2017; 81 (5) Article 90.}

Table 3. Agreement with Factors/Barriers

\begin{tabular}{|c|c|c|c|c|}
\hline \multirow[b]{2}{*}{$\begin{array}{l}\text { Factor/ } \\
\text { Barrier }\end{array}$} & \multicolumn{4}{|c|}{$\begin{array}{c}\text { Agreement with Factor/Barrier } \\
\text { by Decision to Pursue PGT }\end{array}$} \\
\hline & $\begin{array}{c}\text { Yes } \\
(n=443)\end{array}$ & $\begin{array}{c}\text { No } \\
(n=411)\end{array}$ & $\begin{array}{l}\text { Undecided } \\
(n=364)\end{array}$ & $p$ value \\
\hline F1 & .95 & .78 & .89 & $<.001$ \\
\hline F2 & .90 & .66 & .81 & $<.001$ \\
\hline F3 & .91 & .57 & .78 & $<.001$ \\
\hline F4 & .88 & .66 & .80 & $<.001$ \\
\hline F5 & .79 & .69 & .70 & $<.001$ \\
\hline F6 & .78 & .44 & .63 & $<.001$ \\
\hline F7 & .65 & .51 & .76 & $<.001$ \\
\hline F8 & .76 & .71 & .74 & .085 \\
\hline F9 & .85 & .67 & .74 & $<.001$ \\
\hline F10 & .79 & .74 & .76 & .058 \\
\hline F11 & .77 & .62 & .66 & $<.001$ \\
\hline F12 & .76 & .71 & .76 & .019 \\
\hline F13 & .63 & .44 & .55 & $<.001$ \\
\hline F14 & .67 & .50 & .55 & $<.001$ \\
\hline F15 & .85 & .49 & .73 & $<.001$ \\
\hline B1 & .54 & .74 & .73 & .001 \\
\hline B2 & .62 & .78 & .74 & $<.001$ \\
\hline B3 & .54 & .77 & .66 & $<.001$ \\
\hline B4 & .45 & .66 & .57 & $<.001$ \\
\hline B5 & .37 & .54 & .50 & $<.001$ \\
\hline B6 & .45 & .58 & .57 & $<.001$ \\
\hline B7 & .41 & .54 & .49 & $<.001$ \\
\hline B8 & .36 & .47 & .43 & $<.001$ \\
\hline B9 & .38 & .47 & .44 & $<.001$ \\
\hline B10 & .41 & .60 & .56 & $<.001$ \\
\hline B11 & .42 & .58 & .60 & $<.001$ \\
\hline B12 & .48 & .60 & .58 & $<.001$ \\
\hline B13 & .68 & .71 & .76 & $<.001$ \\
\hline B14 & .44 & .54 & .62 & $<.001$ \\
\hline B15 & .51 & .68 & .69 & $<.001$ \\
\hline B16 & .44 & .67 & .57 & $<.001$ \\
\hline B17 & .40 & .50 & .46 & $<.001$ \\
\hline B18 & .35 & .78 & .53 & $<.001$ \\
\hline B19 & .42 & .55 & .56 & $<.001$ \\
\hline
\end{tabular}

PGT $=$ postgraduate training

to the one used in this research was developed to assess subjective task value beliefs regarding the decision to pursue PGT and included domains on intrinsic value and attainment value. ${ }^{15}$ The three items in this instrument that were best associated with pursuit of PGT were in those two domains. Previously surveyed residents and fellows indicated their two largest factors for pursuing PGT were related to SA ("gain knowledge and experience," and "desire for specialized training"). ${ }^{11}$ Additionally, students who desire to achieve SA may consider careers in academia, a clinical practice, or social and administrative responsibilities, as well as pharmacy association management opportunities. ${ }^{16}$ All of these may be easier to achieve after PGT. Faculty and administrators at colleges of pharmacy can develop curricular and cocurricular methods that encourage students to self-evaluate and explore their potential careers more thoroughly and with self-actualization in mind before making decisions on PGT.

In addition to their desire for self-actualization, students who desired to pursue PGT were more aware of PGT opportunities and their benefits than the other groups. This awareness may have originated from multiple sources, including faculty members, non-faculty pharmacists, residents, fellows, other students, pharmacy organizations, and specific programming promoting and describing PGT through numerous venues. There was no statistically significant difference between student perceptions when faculty members emphasized PGT (F8); however, when faculty members de-emphasized PGT or emphasized career paths that do not require PGT, this significantly impacted student perceptions (B9). For students who do not desire a position that requires PGT (B18), this behavior is very appropriate. However, students who were undecided about pursuing PGT had less positive and more negative reinforcement regarding PGT pursuit and likely should receive reinforcement and support for pursuing careers that do and do not require PGT. These previously unreported findings underscore the importance of developing a culture of support, communication, and acceptance within a college of pharmacy. This balance in education on careers will continue to grow in importance as medication therapy management and patient-centered medical home models continue to flourish and attract graduates who previously may not have considered these types of careers. Faculty members should be aware of the messages pharmacy students and pharmacists receive on this topic. Pharmacy school representatives previously indicated that faculty and colleges of pharmacy stress the importance of PGT opportunities, ${ }^{11}$ but this may not be universal or extend beyond the academic environment. Experiential education departments in colleges of pharmacy may help preceptors understand the college's culture regarding PGT, so that students do not receive discordant messages. Colleges of pharmacy also may find ways to increase student interactions with residents and fellows, especially for those students who are undecided about pursuing PGT, to improve their awareness of PGT and appreciation for the benefits and challenges when completing PGT. Opportunities for these interactions occur in all colleges of pharmacy in this sample, may begin before or during introductory pharmacy practices experiences, and should be integrated throughout curricula.

Besides mixed messages pharmacy students may receive regarding PGT, our analysis supported the existence 


\section{American Journal of Pharmaceutical Education 2017; 81 (5) Article 90.}

Table 4. Agreement with Domains

\begin{tabular}{|c|c|c|c|}
\hline \multirow[b]{2}{*}{ Domain } & \multicolumn{3}{|c|}{ Agreement $^{1}$} \\
\hline & Yes for PGT & No for PGT & Undecided for PGT \\
\hline Self-actualization ${ }^{2,3,4}$ & .86 & .39 & .68 \\
\hline Future employment $\&$ growth potential ${ }^{2,3,4}$ & .60 & .35 & .49 \\
\hline Awareness of PGT opportunities ${ }^{2,3}$ & .65 & .47 & .50 \\
\hline Internal Barriers/Factors ${ }^{2,3}$ & .55 & .36 & .37 \\
\hline External Barriers/Factors ${ }^{2,3}$ & .44 & .35 & .35 \\
\hline
\end{tabular}

PGT $=$ postgraduate training

${ }^{1} 0-1$ scale; $0=$ strongly disagree, $1=$ strongly agree

${ }^{2} \mathrm{p}$-value for yes/no comparison $<.001$

${ }^{3} \mathrm{p}$-value for yes/undecided comparison $<.001$

${ }^{4}$ p-value for no/undecided comparison $<.001$

of strong financial disincentives for pharmacy students to pursue PGT, particularly among the impressionable group of students who were undecided. The increasing student loan debt among pharmacy students ${ }^{17}$ has previously been shown to impact career choice after graduation among community pharmacists. ${ }^{18}$ The decidedly lower annual salary for pharmacy residents $(\$ 43,579$ in the US as of December 2015) theoretically may worsen this debt issue when compared to the salary for non-resident pharmacists $\left(\$ 120,926\right.$ in the US as of December 2015). ${ }^{19}$ However, proposed legislation on overtime wages for many working classes, including residents in health care fields, could increase residents' salaries in the near future. ${ }^{20}$ Graduating pharmacy students' fear of debt accrued to finance their training has been well-established. ${ }^{21}$ Existing literature is split on the impact from PGT on future earning potential. A 2011 economic analysis of post-PharmD PhD training showed a negative return on investment in a simulated model. ${ }^{22}$ However, in an economic analysis performed using Markov modeling for lifetime earnings, hospital pharmacists who completed one year of residency training had greater career earnings than those who began working in the hospital after finishing pharmacy school. However, pharmacists who entered the community pharmacy workforce directly after graduation had higher career earnings $(\$ 59,987$ up to age 67$)$ than their residencytrained counterparts. ${ }^{23}$ It is important to note that a strictly economic evaluation cannot place a value on job satisfaction, which may be increased after PGT. ${ }^{24,25}$ Although we did not evaluate students' knowledge of the long-term financial aspects of pursuing PGT, students in all groups may benefit from a more complete assessment of their financial outlooks after graduation.

Financial disincentives may be a major barrier to the pursuit of PGT, but competition for PGT positions (largely residency positions) was the highest-rated barrier among students in our study who plan to pursue PGT and those who were undecided, whereas the belief that the student's extracurricular activities were not competitive enough was a highly rated barrier among students who did not plan to pursue PGT and those who were undecided. Since 2007, the growth in residency applicants has outpaced that of residency programs. ${ }^{26}$ Most concerning is the decrease in applicants who match with their topranked program, which fell from $63 \%$ in 2001 to $38 \%$ in 2015. In 2015, approximately $38 \%$ of graduating students enrolled in the Match, which only included residency programs accredited or pursuing accreditation through ASHP. ${ }^{13,26}$ Similarly, in our cohort, $36 \%$ of students graduating in 2016 indicated a desire to pursue a residency and/or fellowship after graduation, with another $30 \%$ undecided. However, we do not know the true proportion of students who pursued PGT and believe this relationship warrants evaluation.

While a number of IFB domain, non-modifiable barriers significantly affected student opinions [specifically B4 (family obligations) and B6 (geographical limitations)], many modifiable barriers did as well. In all three groups of students, lack of involvement in extracurricular activities was the single highest-rated barrier from this domain, suggesting students did not feel prepared to compete with other candidates based on their involvement. Many respondents in our survey indicated that they felt too busy during pharmacy school to participate in extracurricular activities. Phillips and colleagues reported that up to $82 \%$ of pharmacy students are involved in at least one organization, and $60 \%$ are involved in two or more organizations. ${ }^{27}$ A more rewarding approach for students may involve incorporating components of leadership development into pharmacy curricula, ${ }^{28}$ or implementation of clinical tracks/gateway programs for $\mathrm{PGT}^{29,30}$ Through these mechanisms, students may be able to make the most of their experiences and tailor their time in pharmacy school to best meet their individual needs. However, students and faculty members should consider that residency programs value general leadership experience. ${ }^{31}$ Encouraging PGT 


\section{American Journal of Pharmaceutical Education 2017; 81 (5) Article 90.}

program directors and preceptors to value these clinical tracks/gateway programs as much, or more than, traditional student leadership positions may take time.

Another modifiable barrier was the timing of introduction to PGT. The most common timeframe for PGT to first be introduced to our cohort was in the first professional year of pharmacy school (67.5\%). However, in the $26 \%$ of the cohort who learned about PGT prior to beginning their first professional year, $50.3 \%$ planned to pursue PGT. High school and undergraduate students may begin learning about the pharmacy profession through a variety of avenues, including summer pharmacy camps, ${ }^{32}$ shadowing experiences, ${ }^{33}$ and mentor-protégé relationships within and outside of the profession. ${ }^{34}$ Colleges of pharmacy looking to attract students who may pursue PGT may consider incorporating discussion of these opportunities into their marketing campaigns and interview processes and accept students who express this desire and meet other admission standards. For students already enrolled in a doctor of pharmacy program, establishing effective mentor-protégé relationships for those interested in pursuing PGT has been shown to be impactful. ${ }^{5}$

While our study was the largest to date on pharmacy students' perceived motivations and barriers to pursuing PGT, there were a number of important limitations. First, the response rate was approximately $70 \%$. While this was a more representative sample than previous surveys, ${ }^{11,12}$ it was possible that the in-class survey may have selected students who attend class and may possess different personal characteristics. Additionally, the response rate varied between institutions ( $23 \%$ to $99 \%$ ). In an analysis not presented, the results for institutions with a response rate of less than $70 \%$ did not differ with those greater than $70 \%$, suggesting the students who completed the survey were similar between institutions regardless of response rate. The precise impact these differences could have had on responses was unknown. Shortening the length of the survey could have increased the survey response rate. Additionally, there was a slight over-representation for the South region of the US in our cohort (46\%) compared to accredited colleges of pharmacy (31\%). Although other parts of the country were more appropriately represented, it is possible our results may have differed had we surveyed a more geographically broad population. In particular, because response rates were lower for a program in the Midwestern region and the Western region, these regions may have been under-represented. The effect of this under-representation is unknown. On an individual student level, students' scholastic, scholarship, and leadership achievements were not evaluated. The quality and quantity of these characteristics may have impacted students' decisions to pursue PGT and should be investigated in the future. Moreover, domain identification was conducted by leveraging the expertise of the POLS Network. While this approach does not approach the internal validity of a factor analysis, it allows for identification of domains relevant to faculty members and for the separation of modifiable and non-modifiable factors. Finally, students were surveyed prior to making their final decisions about pursuing PGT and discovering if they had matched or had been accepted into a PGT program. We believe that the group of students that was undecided about pursuing PGT is a group that deserves significant attention from faculty and administrators at colleges of pharmacy. These students could be the most receptive to increased opportunities to learn about PGT and assistance from others to make a decision on pursuing PGT. Surveying after decisions on PGT were made (eg, after the matching process) likely would have greatly reduced or entirely removed this group from our results.

\section{CONCLUSION}

Students who were more aware of PGT options and understood their benefits were more likely to classify themselves as having a desire to pursue PGT. Students who desired to pursue PGT showed higher levels of agreement with all five domains, with the desire to achieve selfactualization in their careers showing the highest degree of agreement. Almost one-third of students were undecided about pursuing PGT. Future research should evaluate how addressing the different perceptions on PGT among pharmacy students affects their desires to pursue such training.

\section{REFERENCES}

1. American Society of Health-System Pharmacists. ASHP policy positions 2009-2016 (with rationales): education and training. https:// www.ashp.org/pharmacy-practice/policy-positions-and-guidelines/. Accessed January 13, 2016.

2. Murphy JE, Nappi JM, Bosso JA, et al. American College of Clinical Pharmacy's vision of the future: postgraduate pharmacy residency training as a prerequisite for direct patient care practice. Pharmacotherapy. 2006;26:722-733.

3. Lee M, Bennet M, Chase P, et al. Final report and recommendations of the 2002 AACP task force on the role of colleges and schools in residency training. Am J Pharm Educ. 2004;68(1): Article S2.

4. Accreditation Council for Pharmacy Education. Accreditation standards and guidelines for the professional program in pharmacy leading to the doctor of pharmacy degree. https://www.acpe-accredit. org/pdf/Standards2016FINAL.pdf. Accessed January 13, 2016.

5. Hammond DA, Garner SS, Linder MA, Cousins WB, Bookstaver PB. Assessment of mentor involvement with pharmacy students pursuing post-graduate residency training. Curr Pharm Teach Learn. 2016;8(1):18-23.

6. Dunn BL, Ragucci KR, Garner SS, Spencer A. Survey of colleges of pharmacy to assess preparation for and promotion of residency training. Am J Pharm Educ. 2010;74(3):Article 43. 


\section{American Journal of Pharmaceutical Education 2017; 81 (5) Article 90.}

7. Bryles PB, Bourg CA, Guffey WJ, Phillips BG. An elective course on postgraduate residency training. Am J Pharm Educ. 2012;76(9): Article 174

8. New J, Garner S, Ragucci K, Spencer A. An advanced clinical track within a doctor of pharmacy program. Am J Pharm Educ. 2012;76(3):Article 43.

9. Stover KR, Fleming LW, Riche DM, Sherman JJ, Bloodworth LS. Impact of a residency interest group on students applying for residency. Am J Pharm Educ. 2014;78(6):Article 127.

10. Rider SK, Oeder JL, Nguyen TT, Rodis JL. A collaborative approach to residency preparation programming for pharmacy students. Am J Health Syst Pharm. 2014;71(11):950-955. 11. McCarthy BC Jr, Weber LM. Update on factors motivating pharmacy students to pursue residency and fellowship training. $\mathrm{Am} \mathrm{J}$ Health Syst Pharm. 2013;70(16):1397-1403.

12. Bucci KK, Knapp KK, Ohri LK, Brooks PJ. Factors motivating pharmacy students to pursue residency and fellowship training. Am J Health Syst Pharm. 1995;52(23):2696-2701.

13. Academic Pharmacy's Vital Statistics. http://www.aacp.org/ about/pages/vitalstats.aspx. Accessed February 6, 2016.

14. Hennessey BA, Amabile TM. Reward, intrinsic motivation, and creativity. Am Pychol. 1998;53(6):674-675.

15. Hagemaier NE, Murawaski MM. An instrument to assess subjective task value beliefs regarding the decision to pursue postgraduate training. Am J Pharm Educ. 2014;78(1):Article 11. 16. Schommer JC, Sogol EM, Brown LM. Identifying work setting profile factors from the Career Pathway Evaluation Program. Am J Pharm Educ. 2013;77(9):Article 194.

17. American Association of Colleges of Pharmacy. Graduating student survey summary report 2013. http://www.aacp.org/resources/ research/institutionalresearch/Documents/2013_GSS_summary\% 20report_all\%20schools_113.pdf. Accessed December 18, 2015. 18. Yusuf AA, Schommer JC, Mott DA, Doucette WR, Gaither CA, Kreling DH. Association between student loan debt on graduation, demographic characteristics, and initial choice of practice setting among pharmacists. Innov Pharm. 2011;2(3):Article 51.

19. Glass Door. www.glassdoor.com. Accessed January 13, 2016. 20. US Department of Labor. Wage and Hour Division. http://www. dol.gov/whd/overtime/NPRM2015/. Accessed March 3, 2016. 21. Park T, Yusuf AA, Hasdall RS. Pharmacy students' attitudes towards debt. Am J Pharm Educ. 2015;79(4):Article 52.
22. Hagemeier NE, Murawaski MM. Economic analysis of earning a PhD degree after completion of a PharmD degree. Am J Pharm Educ. 2011;75(1):Article 15.

23. Chisholm-Burns MA, Gatwood J, Spivey CA. Economic analysis of obtaining a PharmD degree and career as a pharmacist. Am J Pharm Educ. 2015;79(8):Article 117.

24. Liu CS, White L. Key determinants of hospital pharmacy staff's job satisfaction. Res Social Adm Pharm. 2011;7(1):51-63. 25. Lau WM, Pang J, Chui W. Job satisfaction and the association with involvement in clinical activities among hospital pharmacists in Hong Kong. Int J Pharm Pract. $2011 ; 19(4): 253-263$.

26. National Matching Services, Inc. Match statistics. https://www. natmatch.com/ashprmp/aboutstats.html. Accessed December 18, 2015.

27. Phillips JA, McLaughlin MM, Gettig JP, Fajiculay JR, Advincula MR. An analysis of motivation factors for students' pursuit of leadership positions. Am J Pharm Educ. 2015;79(1):Article 8. 28. Chesnut R, Tran-Johnson J. Impact of a student leadership development program. Am J Pharm Educ. 2013;77(10): Article 225.

29. New J, Garner S, Ragucci K, Spencer A. An advanced clinical track within a doctor of pharmacy program. Am J Pharm Educ. 2012;76(3):Article 43.

30. Bodenberg M, Linn B, Sprunger T, Shepler B. Using institutional track programs and block scheduling to help students prepare for postgraduate residency training. Am J Health Syst Pharm 2015; 72(22):1969-1973.

31. Ensor CR, Walker CL, Rider SK, Clemente EU, Ashby DM, Shermock KM. Streamlining the process for initial review of pharmacy residency applications: an analytic approach. Am J Health Syst Pharm. 2013;70(19):1670-1675.

32. Pharmacy camp. http://pharmcollege.uams.edu/prospectivestudents/pharmacy-camp/. Accessed January 13, 2016.

33. Positioning yourself to succeed in pharmacy: legal and regulatory considerations. http://docplayer.net/3056541-Positioningyourself-to-succeed-in-pharmacy-legal-and-regulatoryconsiderations.html. Accessed January 13, 2016.

34. Hammond DA, DiPiro JT. Influential aspects of the mentor in a mentor-mentee relationship. South Carolina Society of HealthSystem Pharmacists. Abstract. 


\section{American Journal of Pharmaceutical Education 2017; 81 (5) Article 90.}

Appendix 1. Survey Instrument

Q1 Our research team is conducting a multicenter study to determine the factors motivating pharmacy students to pursue postgraduate residency or fellowship training and the barriers pharmacy students perceive exist to pursuing postgraduate residency or fellowship training. We would like to invite you, regardless of your intentions to pursue postgraduate training, to participate. This survey has been tested by other faculty members and pharmacy students and should take no more than 10 minutes to complete. The results will be used to evaluate pharmacy education both on a local and an international basis. Your participation is voluntary, and neither your decision whether or not to participate nor your survey responses will have any bearing on your academic or professional status.

I agree to participate.

I do not wish to participate.

Q2 What is your current age in years?

Q3 What is your gender?

Male

Female

Q4 Pharmacy is my first career:

No

Yes

Q5 I possess the following degrees (select all that apply):

None

Associate

Bachelor

Master

Doctorate

Q6 I am enrolled in the following dual degree program (please select all that apply):

None

PharmD/JD

PharmD/MBA

PharmD/MHA

PharmD/MHIT

PharmD/MPH

PharmD/MS

PharmD/PA

PharmD/PhD

PharmD/other (please specify)

Q7 In which year did you FIRST begin seriously considering your primary career path post-graduation?

Undecided

Pre-professional curriculum

While working in a previous career

First

Second

Third

Q8 I have worked at least 6 total months (part-time or full-time) in the following areas (please select all that apply):

None

Community Pharmacy

Hospital Pharmacy

Pharmaceutical Industry

Nuclear Pharmacy

Home Infusion

Non-Pharmacy area

Other (specify) 


\section{American Journal of Pharmaceutical Education 2017; 81 (5) Article 90.}

Q9 I am enrolled in a pre-clinical, pre-residency or pre-fellowship track or pathway:

No

Yes

Q10 In which professional year did you FIRST learn about postgraduate training options (e.g., residencies and/or fellowships)?

Did not learn

Pre-professional curriculum

First

Second

Third

Q11 In which professional year do you believe it would be BEST for programs to introduce students to the possibility of pursuing a residency or fellowship?

Do not introduce

Pre-professional curriculum

First

Second

Third

Q12 Which method(s) does your program use to promote postgraduate residency and/or fellowship training? (Please select all that apply.)

Formal instruction by faculty members in the curriculum

Informal instruction by faculty members outside of the curriculum

Involvement of residency or fellowship preceptors in clerkship teaching

Student-advisor or student-mentor program

Professional organizations

Other (please specify)

Q13 I DO plan to complete postgraduate training (eg, residency and/or fellowship) upon graduation from pharmacy school.

No

Yes

Undecided

Answer If I DO plan to complete postgraduate training (eg, residency and/or fellowship) upon graduation from pharmacy school. Yes Is Selected Or I DO plan to complete postgraduate training (eg, residency and/or fellowship) upon graduation from pharmacy school. Undecided Is Selected

Q14 Which type(s) of residency are you considering? (Please select all that apply.)

Community

Managed Care

Hospital (acute care focus)

Hospital (ambulatory care focus)

Other (specify)

Answer If I DO plan to complete postgraduate training (eg, residency and/or fellowship) upon graduation from pharmacy school. Yes Is Selected Or I DO plan to complete postgraduate training (eg, residency and/or fellowship) upon graduation from pharmacy school. Undecided Is Selected

Q15 Do you plan on completing a PGY2 specialty residency?

No

Yes

Undecided

Answer If I DO plan to complete postgraduate training (eg, residency and/or fellowship) upon graduation from pharmacy school. Yes Is Selected Or I DO plan to complete postgraduate training (eg, residency and/or fellowship) upon graduation from pharmacy school. Undecided Is Selected 


\section{American Journal of Pharmaceutical Education 2017; 81 (5) Article 90.}

Q16 Which type(s) of fellowship are you considering? (Please select all that apply.)

31 None (1)

32 Clinical area (eg, toxicology, infectious diseases) (2)

33 Pharmaceutical Industry (3)

34 Other (specify) (4)

Q17 Please complete both of the following sections, regardless of whether you are considering postgraduate training after you graduate with your Doctor of Pharmacy degree. Please indicate your level of agreement or disagreement with each of the following potential advantages and limitations regarding how they may have influenced your decision on whether or not to pursue postgraduate training.

I am considering or have considered completing postgraduate training because of the following factors:

$1=$ strongly disagree, $2=$ disagree $3=$ neither agree nor disagree, $4=$ agree, $5=$ strongly agree

I believe my student loans or other financial obligations after graduation will be too significant.

I believe the salaries offered during postgraduate training are too low.

I believe further training is required for obtaining the position I desire in the future.

I believe further training is needed due to new and challenging roles pharmacists may have in the future.

I desire a position similar to that of a pharmacist whom I consider a role model.

I desire to be employed at an institution that requires postgraduate training experience.

I am undecided about my future plans and feel that additional education and training will better prepare me for many areas of practice.

Faculty members stressed the importance of postgraduate training.

I have had positive interactions with residents and/or fellows while in pharmacy school.

My college of pharmacy stressed the importance of postgraduate training.

A mentor or advisor stressed the importance of postgraduate training.

My peers are considering completing postgraduate training.

My employer or coworkers stressed the importance of postgraduate training.

The job opportunities in my local area (or the area I desire to live and work) all require postgraduate training.

I desire to complete further training for personal satisfaction.

Other (please specify)

Q18 I am NOT considering or have NOT considered completing postgraduate training because of the following factors:

$1=$ strongly disagree, $2=$ disagree $3=$ neither agree nor disagree, $4=$ agree, $5=$ strongly agree

I believe my student loans or other financial obligations after graduation will be too significant.

I believe the salaries offered during postgraduate training are too low.

There will be a job available for me after graduation.

I believe my family obligations after graduation will be too significant.

The long-term benefits of completing postgraduate training have not been stressed to me.

I believe my geographical limitations will be too significant.

My employer or coworker stressed that postgraduate training is not important.

A mentor or advisor stressed that postgraduate training is not important.

Faculty members in my college of pharmacy stressed the importance of other career paths that do not require postgraduate training.

I have been too busy during pharmacy school to consider pursuing postgraduate training.

I believe I would be beginning the process of pursuing postgraduate training too late.

I believe my grades are prohibitive to me pursuing postgraduate training.

The competition for postgraduate training positions is too high.

I do not know enough about postgraduate training opportunities.

I believe my extracurricular activities are not competitive enough for me to pursue postgraduate training.

I believe I can get a job without postgraduate training that other people believe requires postgraduate training.

My peers are not considering completing postgraduate training.

I do not desire a position that requires postgraduate training.

I do not feel prepared to complete postgraduate training.

Other (please specify) 


\section{American Journal of Pharmaceutical Education 2017; 81 (5) Article 90.}

Appendix 2. Factor/Barrier Descriptions \& Domains

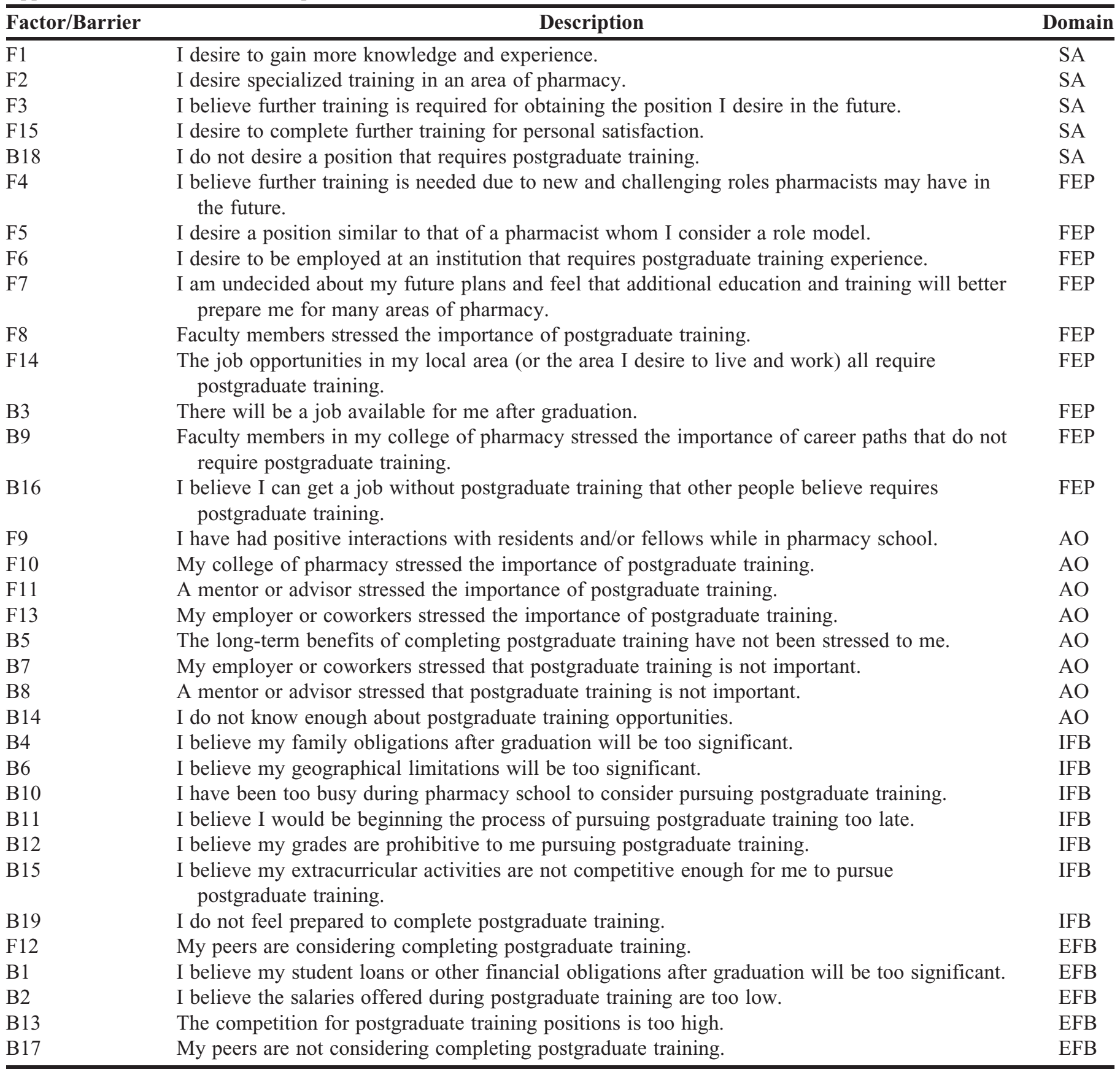

$\mathrm{F}=$ factor; $\mathrm{B}=$ barrier; $\mathrm{SA}=$ self-actualization; FEP $=$ future employment/growth potential; $\mathrm{AO}=$ awareness of PGT opportunities; IFB = internal factors/barriers influencing application for PGT; EFB = external factors/barriers influencing application for PGT; PGT = postgraduate training 


\section{American Journal of Pharmaceutical Education 2017; 81 (5) Article 90.}

Appendix 3. Direct Comparisons Between Groups for Agreement with Factors/Barriers by Decision to Pursue PGT

\begin{tabular}{|c|c|c|c|c|c|c|c|c|c|}
\hline \multirow[b]{2}{*}{$\begin{array}{l}\text { Factor/ } \\
\text { Barrier }\end{array}$} & \multicolumn{3}{|c|}{ Yes vs No } & \multicolumn{3}{|c|}{ Yes vs Undecided } & \multicolumn{3}{|c|}{ No vs Undecided } \\
\hline & $\begin{array}{c}\text { Yes } \\
(n=443)\end{array}$ & $\begin{array}{c}\text { No } \\
(n=411)\end{array}$ & $p$ value & $\begin{array}{c}\text { Yes } \\
(n=443)\end{array}$ & $\begin{array}{c}\text { Undecided } \\
(\mathrm{n}=364)\end{array}$ & $p$ value & $\begin{array}{c}\text { No } \\
(n=411)\end{array}$ & $\begin{array}{c}\text { Undecided } \\
(\mathrm{n}=364)\end{array}$ & $p$ value \\
\hline$\overline{\mathrm{F} 1}$ & .5 & .78 & $<.001$ & .95 & .89 & $<.001$ & .78 & .89 & $<.001$ \\
\hline $\mathrm{F} 2$ & .9 & .66 & $<.001$ & .9 & .81 & $<.001$ & .66 & .81 & $<.001$ \\
\hline F3 & .91 & .57 & $<.001$ & .91 & .78 & $<.001$ & .57 & .78 & $<.001$ \\
\hline F4 & .88 & .66 & $<.001$ & .88 & .8 & $<.001$ & .66 & .8 & $<.001$ \\
\hline F5 & .79 & .69 & $<.001$ & .79 & .7 & $<.001$ & .69 & .7 & .43 \\
\hline F6 & .78 & .44 & $<.001$ & .78 & .63 & $<.001$ & .44 & .63 & $<.001$ \\
\hline F7 & .65 & .51 & $<.001$ & .65 & .76 & $<.001$ & .51 & .76 & $<.001$ \\
\hline F8 & .76 & .71 & .055 & .76 & .74 & .1 & .71 & .74 & .25 \\
\hline F9 & .85 & .67 & $<.001$ & .85 & .74 & $<.001$ & .67 & .74 & $<.001$ \\
\hline F10 & .79 & .74 & .002 & .79 & .76 & .029 & .74 & .76 & .31 \\
\hline F11 & .77 & .62 & $<.001$ & .77 & .66 & $<.001$ & .62 & .66 & .014 \\
\hline F12 & .76 & .71 & .002 & .76 & .76 & .88 & .71 & .76 & .003 \\
\hline F13 & .63 & .44 & $<.001$ & .63 & .55 & $<.001$ & .44 & .55 & $<.001$ \\
\hline F14 & .67 & .5 & $<.001$ & .67 & .55 & $<.001$ & .5 & .55 & $<.001$ \\
\hline F15 & .85 & .49 & $<.001$ & .85 & .73 & $<.001$ & .49 & .73 & $<.001$ \\
\hline B1 & .54 & .74 & $<.001$ & .54 & .73 & $<.001$ & .74 & .73 & .71 \\
\hline B2 & .62 & .78 & $<.001$ & .62 & .74 & $<.001$ & .78 & .74 & .079 \\
\hline B3 & .54 & .77 & $<.001$ & .54 & .66 & $<.001$ & .77 & .66 & $<.001$ \\
\hline B4 & .45 & .66 & $<.001$ & .45 & .57 & $<.001$ & .66 & .57 & $<.001$ \\
\hline B5 & .37 & .54 & $<.001$ & .37 & .5 & $<.001$ & .54 & .5 & .043 \\
\hline B6 & .45 & .58 & $<.001$ & .45 & .57 & $<.001$ & .58 & .57 & .82 \\
\hline B7 & .41 & .54 & $<.001$ & .41 & .49 & $<.001$ & .54 & .49 & .014 \\
\hline B8 & .36 & .47 & $<.001$ & .36 & .43 & $<.001$ & .47 & .43 & .002 \\
\hline B9 & .38 & .47 & $<.001$ & .38 & .44 & $<.001$ & .47 & .44 & .056 \\
\hline B10 & .41 & .6 & $<.001$ & .41 & .56 & $<.001$ & .6 & .56 & .019 \\
\hline B11 & .42 & .58 & $<.001$ & .42 & .6 & $<.001$ & .58 & .6 & .46 \\
\hline B12 & .48 & .6 & $<.001$ & .48 & .58 & $<.001$ & .6 & .58 & .16 \\
\hline B13 & .68 & .71 & .067 & .68 & .76 & $<.001$ & .71 & .76 & .009 \\
\hline B14 & .44 & .54 & $<.001$ & .44 & .62 & $<.001$ & .54 & .62 & $<.001$ \\
\hline B15 & .51 & .68 & $<.001$ & .51 & .69 & $<.001$ & .68 & .69 & .77 \\
\hline B16 & .44 & .67 & $<.001$ & .44 & .57 & $<.001$ & .67 & .57 & $<.001$ \\
\hline B17 & .4 & .5 & $<.001$ & .4 & .46 & $<.001$ & .5 & .46 & .017 \\
\hline B18 & .35 & .78 & $<.001$ & .35 & .53 & $<.001$ & .78 & .53 & $<.001$ \\
\hline B19 & .42 & .55 & $<.001$ & .42 & .56 & $<.001$ & .55 & .56 & .28 \\
\hline
\end{tabular}

PGT $=$ Postgraduate Training 